Supporting Information for

\title{
Anion Exchange of Ruddlesden-Popper Lead Halide Perovskites Produces Stable Lateral Heterostructures
}

Chris R. Roy ${ }^{\dagger}$, Dongxu Pan ${ }^{\dagger}$, Yining Wang ${ }^{\ddagger}$, Matthew P. Hautzinger ${ }^{\dagger}$, Yuzhou Zhao ${ }^{\dagger}$, John C. Wright ${ }^{\dagger}$, Zihua Zhu*, and Song Jin $^{\dagger *}$

†Department of Chemistry, University of Wisconsin - Madison, 1101 University Avenue, Madison, Wisconsin 53706, United States

Environmental Molecular Sciences Laboratory, Pacific Northwest National Laboratory, 902 Battelle Boulevard, Richland, Washington 99352, United States 


\section{Additional notes about the synthesis procedures and safety and equipment considerations}

\section{Hazards and damage risks associated with aqueous droplet growth}

The hydroiodic acid (HI) precursor solutions used in the aqueous droplet synthesis of perovskite microplates are corrosive, toxic, and volatile when heated. Beyond the normal precautions to be taken during the solution-based synthesis of lead halide perovskites ${ }^{1}$, it is suggested that additional measures be taken to protect the microscope from contamination and damage:

- Microscope objective lenses with working distances below $1 \mathrm{~cm}$ risk being damaged by HI fumes over repeated droplet syntheses. An inexpensive stereo microscope is ideal for this synthesis, but we have observed no damage to a $1 \mathrm{~cm}$ working distance objective lens after hundreds of droplet syntheses. A cover slip or plastic barrier between the lens and the sample may also suffice.

- The microscope should be cleaned with a lead cleaning solution or soapy water near the dispensation zone to avoid contaminating the microscope over repeated droplet syntheses.

Notes about the design and operation of a vapor-solid anion exchange reactor

The VSAE reactor need not be assembled in the exact manner described in the methods, but through optimizing the reactor, we identified some important attributes that should remain as essential components of any derivative of this type of apparatus:

- The main utility of the desiccant is preventing the formation of moisture droplets in the reaction chamber, not the complete removal of the water vapor (which is likely very difficult). Other chambers capable of preventing vapor accumulation and condensation can also work, such a large drying tower packed loosely with glass wool. If desiccant is chosen to attenuate the accumulation of moisture, Drierite ${ }^{\circledR}$ or similar $\mathrm{Ca}\left(\mathrm{SO}_{4}\right)$ desiccants should be used, because other common desiccants such as silica beads and molecular sieves can be destroyed by reacting with the $\mathrm{HBr}$ in the vapor.

- The reactor must be regularly cleaned to prevent the accumulation of moisture/condensation in the tubing, so it is valuable during extended reactions to have multiple sets of tubing available and ready to be swapped.

- An adequate seal through the entire apparatus with an inhibitor of flow through the outlet (i.e., a bubbler) is necessary to maintain positive pressure in the reactor. In our setup, the bubbler containing saturated sodium bicarbonate solution fulfilled this role. The sodium bicarbonate also scavenges the $\mathrm{HBr}$ or HI outgassed. 


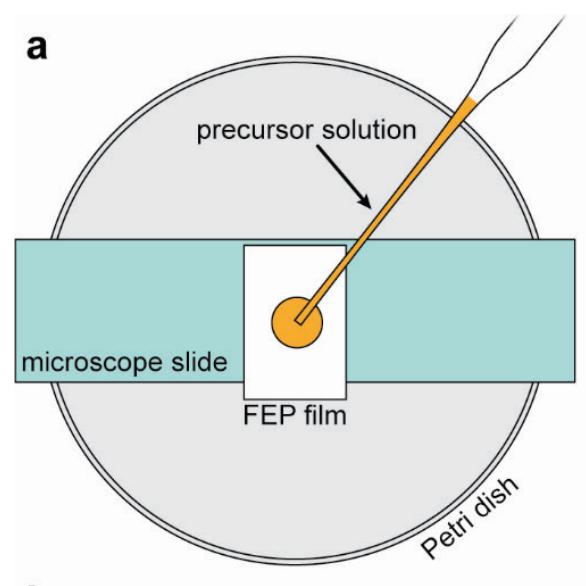

b

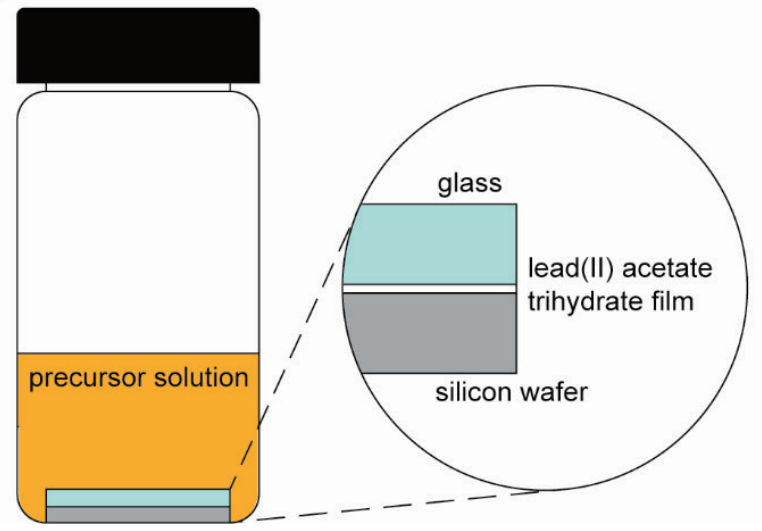

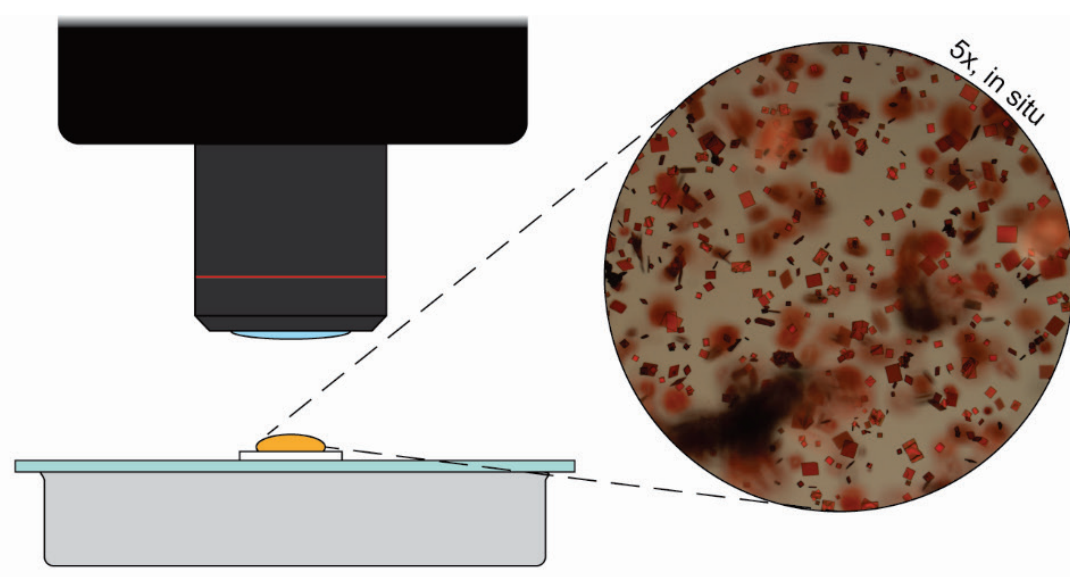

C

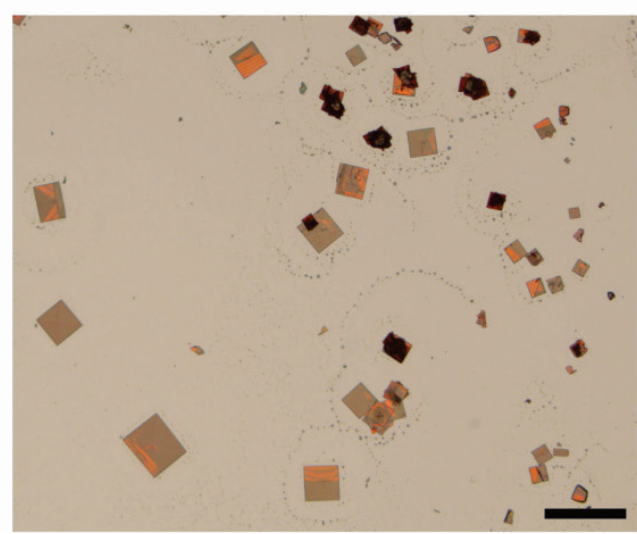

Figure S1. Synthesis methods for RPP microplates. (a) Scheme of the reaction setup for the aqueous droplet growth method. Inset image on the right shows an optical image of the directly monitored synthesis of a sample of $(\mathrm{HA})_{2}(\mathrm{FA}) \mathrm{Pb}_{2} \mathrm{I}_{7}$ microplates. (b) Schematic illustration of the reaction setup for the solution transport growth method in isopropanol (IPA) solution. (c) Optical micrograph of the (HA) $)_{2}(\mathrm{FA}) \mathrm{Pb}_{2} \mathrm{I}_{7}$ microplates synthesized via solution transport prior to washing with IPA. Scale bar is $500 \mu \mathrm{m}$.

Table S1. Parameters for the synthesis of halide perovskite microplates and microcrystals via directly monitored aqueous droplet growth.

\begin{tabular}{|c|r|r|r|c|c|}
\hline Compound & {$[\mathbf{L A I}] \mathbf{( m M )}$} & {$[\mathbf{A I}] \mathbf{( m M )}$} & {$\left[\mathbf{P b I}_{2}\right](\mathbf{m M})$} & $\mathbf{V}(\boldsymbol{\mu L} \mathbf{L})$ & $\mathbf{T}\left({ }^{\circ} \mathbf{C}\right)$ \\
\hline$\left(\mathrm{C}_{6} \mathrm{H}_{13} \mathrm{NH}_{3}\right)_{2} \mathrm{PbI}_{4}$ & 222 & - & 450 & 200 & 35 \\
\hline$\left(\mathrm{C}_{6} \mathrm{H}_{13} \mathrm{NH}_{3}\right)_{2}\left(\mathrm{CH}_{3} \mathrm{NH}_{3}\right) \mathrm{Pb}_{2} \mathrm{I}_{7}$ & 150 & 250 & 500 & 300 & 40 \\
\hline$\left(\mathrm{C}_{6} \mathrm{H}_{13} \mathrm{NH}_{3}\right)_{2}\left(\mathrm{CH}_{3} \mathrm{NH}_{3}\right)_{2} \mathrm{~Pb}_{3} \mathrm{I}_{10}$ & 83 & 417 & 500 & 300 & 40 \\
\hline$\left(\mathrm{C}_{6} \mathrm{H}_{13} \mathrm{NH}_{3}\right)_{2}\left(\mathrm{CH}_{3} \mathrm{NH}_{3}\right)_{3} \mathrm{~Pb}_{4} \mathrm{I}_{13}$ & 33 & 467 & 500 & 300 & 40 \\
\hline$\left(\mathrm{C}_{4} \mathrm{H}_{9} \mathrm{NH}_{3}\right)_{2} \mathrm{PbI}_{4}$ & 250 & - & 500 & 300 & 40 \\
\hline$\left(\mathrm{C}_{8} \mathrm{H}_{9} \mathrm{NH}_{3}\right)_{2} \mathrm{PbI}_{4}$ & 50 & - & 500 & 300 & 40 \\
\hline$\left(\mathrm{C}_{6} \mathrm{H}_{13} \mathrm{NH}_{3}\right)_{2}\left(\mathrm{CH}_{5} \mathrm{~N}_{2}\right) \mathrm{Pb}_{2} \mathrm{I}_{7}$ & 50 & 125 & 450 & 200 & 38 \\
\hline$\left(\mathrm{C}_{6} \mathrm{H}_{13} \mathrm{NH}_{3}\right)_{2}\left(\mathrm{CH}_{6} \mathrm{~N}_{3}\right) \mathrm{Pb}_{2} \mathrm{I}_{7}$ & 80 & 320 & 500 & 300 & 40 \\
\hline$\left(\mathrm{C}_{6} \mathrm{H}_{13} \mathrm{NH}_{3}\right)_{2}\left(\mathrm{CH}_{5} \mathrm{~N}_{2}\right) \mathrm{Pb}_{2} \mathrm{Br}_{7}$ & 62 & 188 & 500 & 300 & 40 \\
\hline$\left(\mathrm{CH}_{3} \mathrm{NH}_{3}\right) \mathrm{PbI}_{3}$ & - & 600 & 500 & 300 & 40 \\
\hline
\end{tabular}



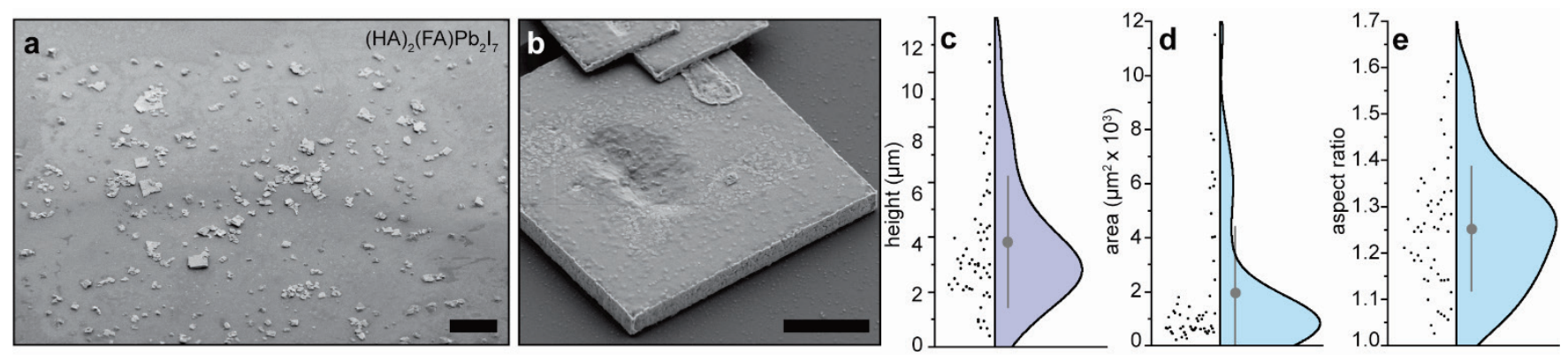

Figure S2. Morphology distribution of RPP microplates. (a, b) Low magnification tilted SEM images of $(\mathrm{HA})_{2}(\mathrm{FA}) \mathrm{Pb}_{2} \mathrm{I}_{7}$ microplates grown on $\mathrm{Si}$ wafer via solution transport. Scale bars are $100 \mu \mathrm{m}$ for a and $10 \mu \mathrm{m}$ for b. (c-e) Half violin plots showing statistics for measurements of (c) microplate heights of $n=$ $2 \mathrm{HA}-\mathrm{FA}-\mathrm{Pb}-\mathrm{I}$ samples grown via solution transport, (d) microplate top face areas of a $n=2 \mathrm{HA}-\mathrm{FA}-\mathrm{Pb}-$ I sample grown via aqueous droplet growth, (e) lateral aspect ratios for the same microplate samples as in $\mathrm{d}$. The distribution curves are kernel density estimates. Large gray dots and bars represent the mean and standard deviation, respectively. 

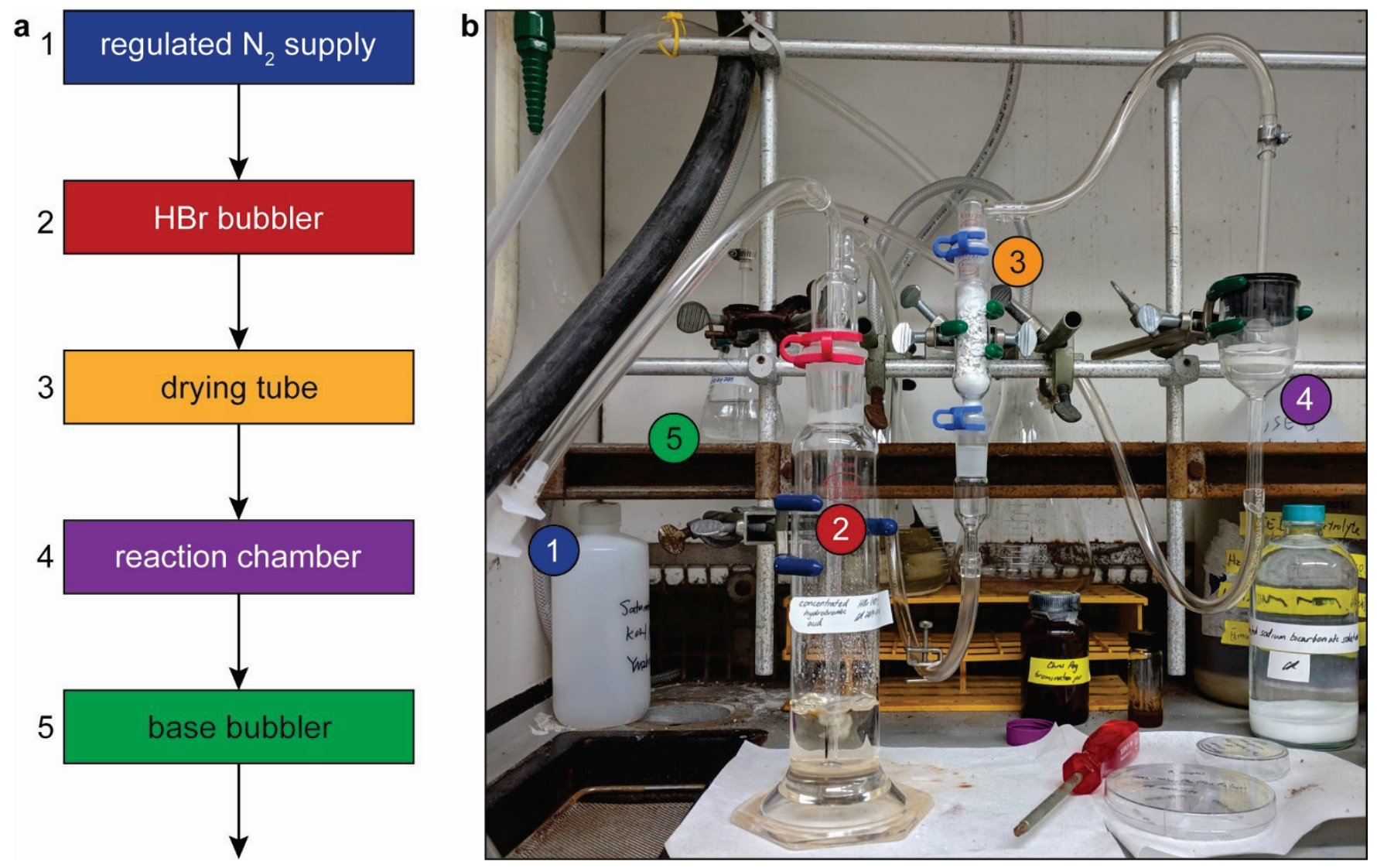

Figure S3. Illustration and photo of the vapor-solid anion exchange (VSAE) reactor. (a) Flow chart of the components of the VSAE reactor, ordered in flow direction of the carrier gas. (b) Photograph of the VSAE reactor during operation, with numbered labels corresponding to the order of the flow chart in a. 

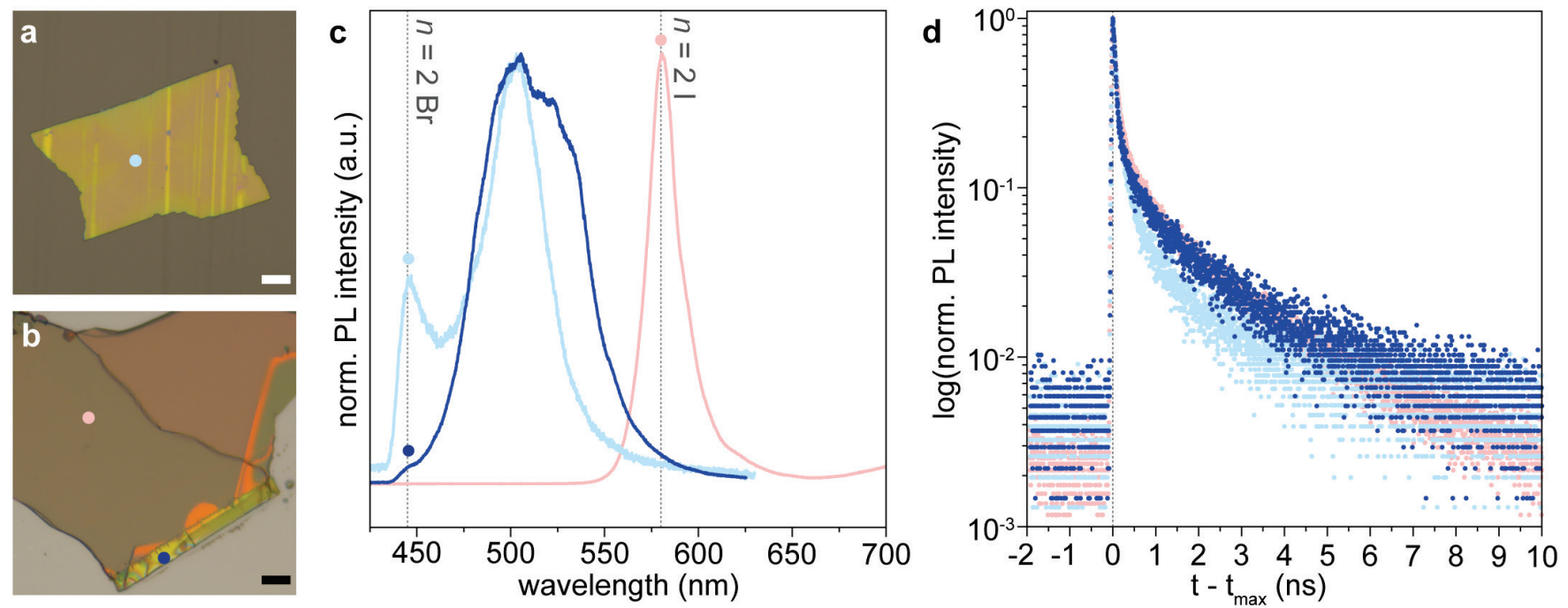

Figure S4. Comparison of the pure $(\mathrm{HA})_{2}(\mathrm{FA}) \mathrm{Pb}_{2} \mathrm{Br}_{7}$ microplate directly synthesized and the converted $(\mathrm{HA})_{2}(\mathrm{FA}) \mathrm{Pb}_{2} \mathrm{Br}_{7}$ phase in an anion-exchanged heterostructure. (a, b) Optical micrographs of (a) a microplate of $(\mathrm{HA})_{2}(\mathrm{FA}) \mathrm{Pb}_{2} \mathrm{Br}_{7}$ directly synthesized via aqueous droplet growth and (b) an exfoliated layer of a $(\mathrm{HA})_{2}(\mathrm{FA}) \mathrm{Pb}_{2} \mathrm{I}_{7}-(\mathrm{HA})_{2}(\mathrm{FA}) \mathrm{Pb}_{2} \mathrm{Br}_{7}$ heterostructure prepared via anion exchange with $\mathrm{HBr}$ vapor. Scale bars are $10 \mu \mathrm{m}$. (c) PL spectra corresponding to the colored spots in panels a $\& \mathrm{~b}$. The peak at $\sim 500 \mathrm{~nm}$ is also present in the directly synthesized pure (HA) $)_{2}(\mathrm{FA}) \mathrm{Pb}_{2} \mathrm{Br}_{7}$ microplate sample, which is attributed to an emissive defect state. Note that the asymmetric blue shoulders of the $445 \mathrm{~nm}$ peaks are due to the cut-off wavelength of a long-pass filter used to attenuate the incident laser light. (d) TRPL transients at the spots marked in $\mathrm{a} \& \mathrm{~b}$ and the peak wavelengths indicated with dots in $\mathrm{c}$.

Table S2. Biexponential fitting parameters for the TRPL transients shown in Figure S4d using $I(t)=A_{1} e^{-t / \tau_{1}}+A_{2} e^{-t / \tau_{2}}$. The time range of 0-10 ns past peak intensity was used for fitting.

\begin{tabular}{|c|c|c|c|c|c|}
\hline Sample & $\mathbf{A}_{\mathbf{1}}$ & $\boldsymbol{\tau}_{\mathbf{1}}(\mathbf{n s})$ & $\mathbf{A}_{\mathbf{2}}$ & $\boldsymbol{\tau}_{\mathbf{2}}(\mathbf{n s})$ & $\mathbf{R}^{\mathbf{2}}$ \\
\hline Directly Synthesized $(\mathrm{HA})_{2}(\mathrm{FA}) \mathrm{Pb}_{2} \mathrm{Br}_{7}$ & 0.92 & 0.08 & 0.12 & 0.83 & 0.993 \\
\hline Exchanged $(\mathrm{HA})_{2}(\mathrm{FA}) \mathrm{Pb}_{2} \mathrm{Br}_{7}$ & 0.89 & 0.07 & 0.14 & 1.22 & 0.995 \\
\hline$(\mathrm{HA})_{2}(\mathrm{FA}) \mathrm{Pb}_{2} \mathrm{I}_{7}$ & 0.84 & 0.09 & 0.17 & 1.21 & 0.997 \\
\hline
\end{tabular}




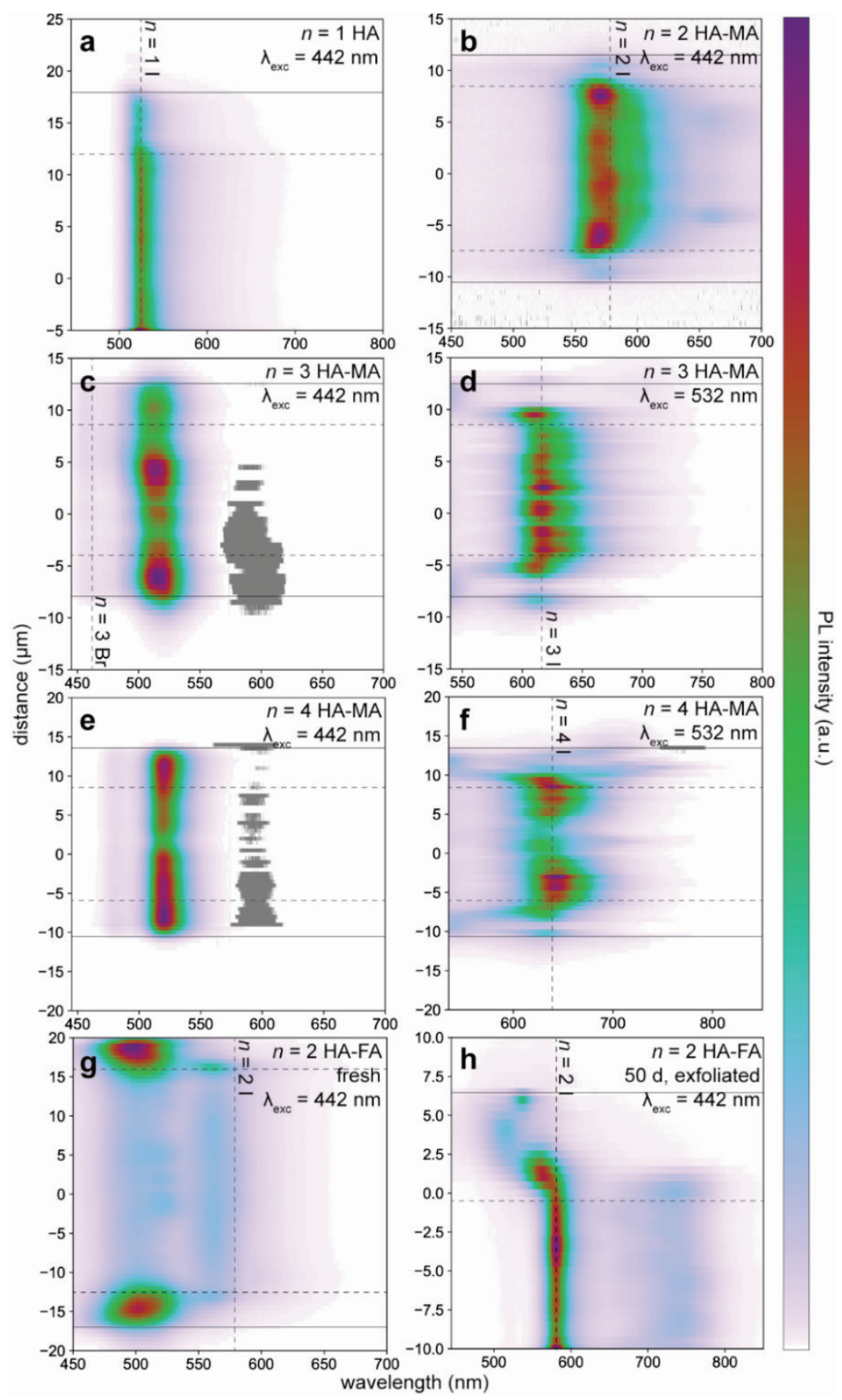

Figure S5. Additional PL line scans of exchanged lateral heterostructures. Confocal PL line scans across the lateral profiles of various RPP microplates after anion exchange with HBr vapor: (a) Extended data for the $n=1 \mathrm{HA}-\mathrm{Pb}-\mathrm{I} / \mathrm{Br}$ heterostructure shown in main text Figure 1f. (b) The entire profile of a $n=2$ $\mathrm{HA}-\mathrm{MA}-\mathrm{Pb}-\mathrm{I} / \mathrm{Br}$ heterostructure. (c, d) The entire profile of a $n=3 \mathrm{HA}-\mathrm{MA}-\mathrm{Pb}-\mathrm{I} / \mathrm{Br}$ heterostructure under (c) $442 \mathrm{~nm}$ excitation and (d) $532 \mathrm{~nm}$ excitation. (e, f) The entire profile of a $n=4 \mathrm{HA}-\mathrm{MA}-\mathrm{Pb}-\mathrm{I} / \mathrm{Br}$ heterostructure under (e) $442 \mathrm{~nm}$ excitation and (f) $532 \mathrm{~nm}$ excitation. (g) An $n=2 \mathrm{HA}-\mathrm{FA}-\mathrm{Pb}-\mathrm{I} / \mathrm{Br}$ heterostructure. (h) An exfoliated layer from an $n=2 \mathrm{HA}-\mathrm{FA}-\mathrm{Pb}-\mathrm{I} / \mathrm{Br}$ heterostructure that has been kept in ambient conditions for 50 days. Dashed and solid horizontal reference lines indicate the junctions and edges of each heterostructure, respectively. Vertical reference lines are placed at known characteristic emission wavelengths of I and Br RPP phases relevant to the subject of each scan. 

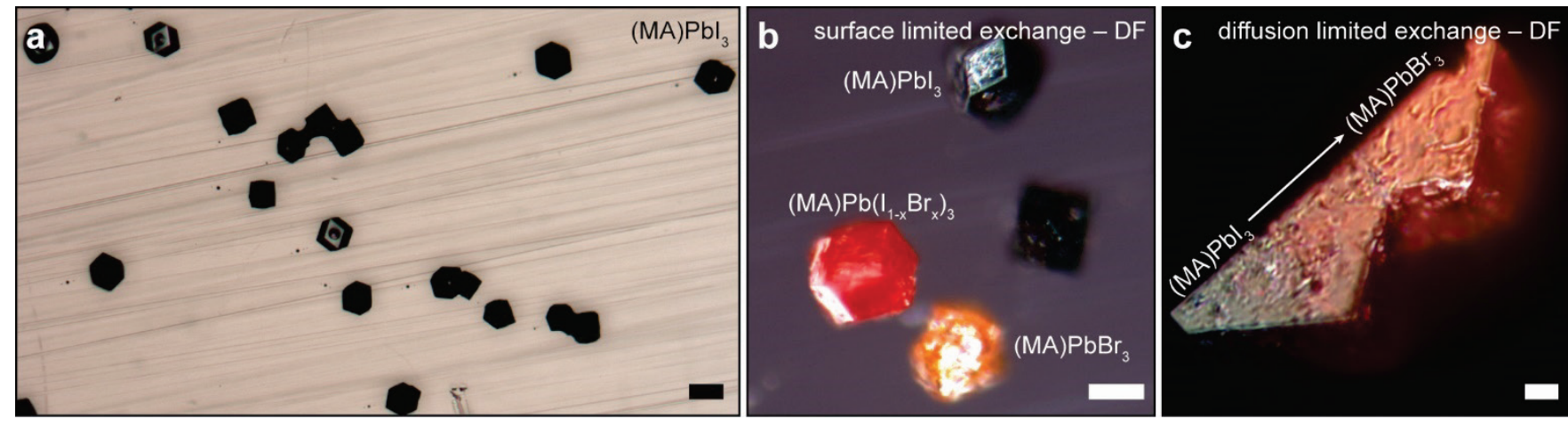

Figure S6. Optical micrographs of $\mathrm{MAPbI}_{3}$ microcrystals before and after $\mathrm{HBr}$ vapor-solid anion exchange. (a) $\mathrm{MAPbI}_{3}$ microcrystals grown via aqueous droplet growth before exchange. Scale bar is 100 $\mu \mathrm{m}$. (b) Outcome of a surface limited anion exchange reaction with several $\mathrm{MAPbI}_{3}$ microcrystals (dark field). (c) Outcome of a diffusion limited anion exchange reaction with a $\mathrm{MAPbI}_{3}$ microcrystal (dark field). There is a visible gradient from $\mathrm{MAPbI}_{3}$ to $\mathrm{MAPbBr}_{3}$ in the crystal. Scale bars in b \& c are $10 \mu \mathrm{m}$. 


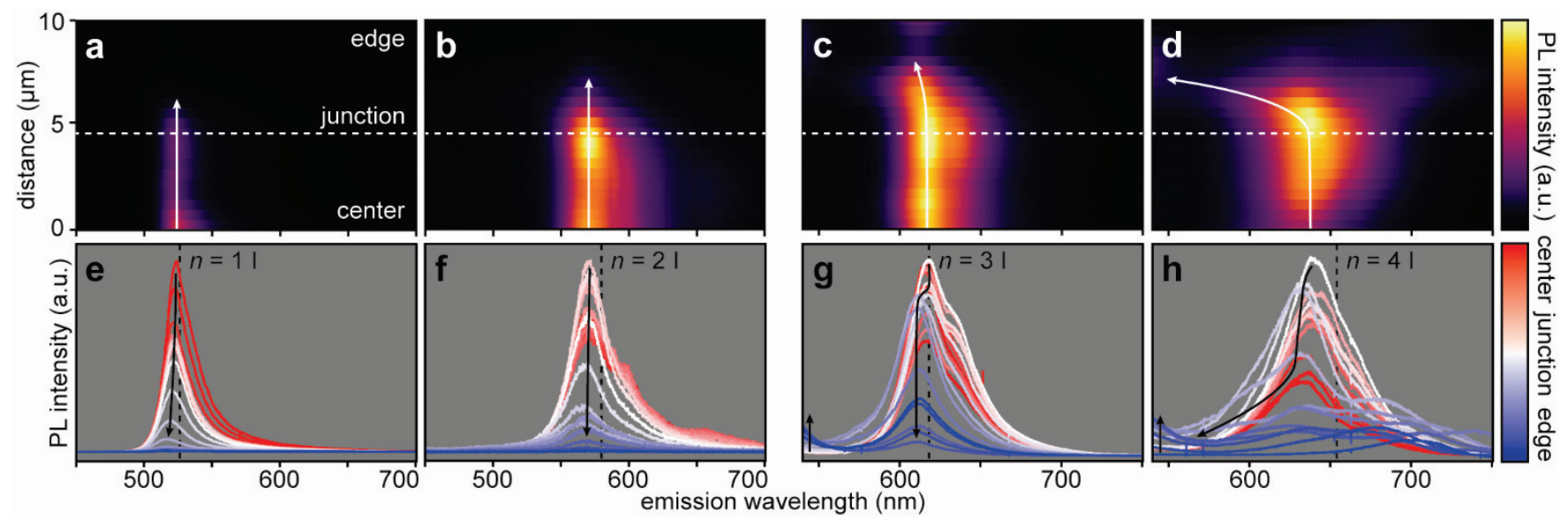

Figure S7. Spectral decompositions of PL linescans across the phase boundaries of various $n=1-4$ HA$\mathrm{MA}-\mathrm{Pb}-\mathrm{I} / \mathrm{Br}$ heterostructures. (a-d) Confocal PL line scans across the junctions of heterostructures analogous to those shown in Figure $1 \mathrm{~b}$-e (but these are not the same specific microplates). a $\&$ b were excited at $442 \mathrm{~nm}$; c \& d were excited at $532 \mathrm{~nm}$. White arrows are visual guides to track spectral shifts across the junctions. (e-h) Individual spectra from distance slices of the line scans shown in a-d. Vertical reference lines indicate the characteristic emission wavelengths for pure iodide analogues of the RPPs presented; black arrows track the intensity and central wavelength of the spectra from the junction to the edge. 

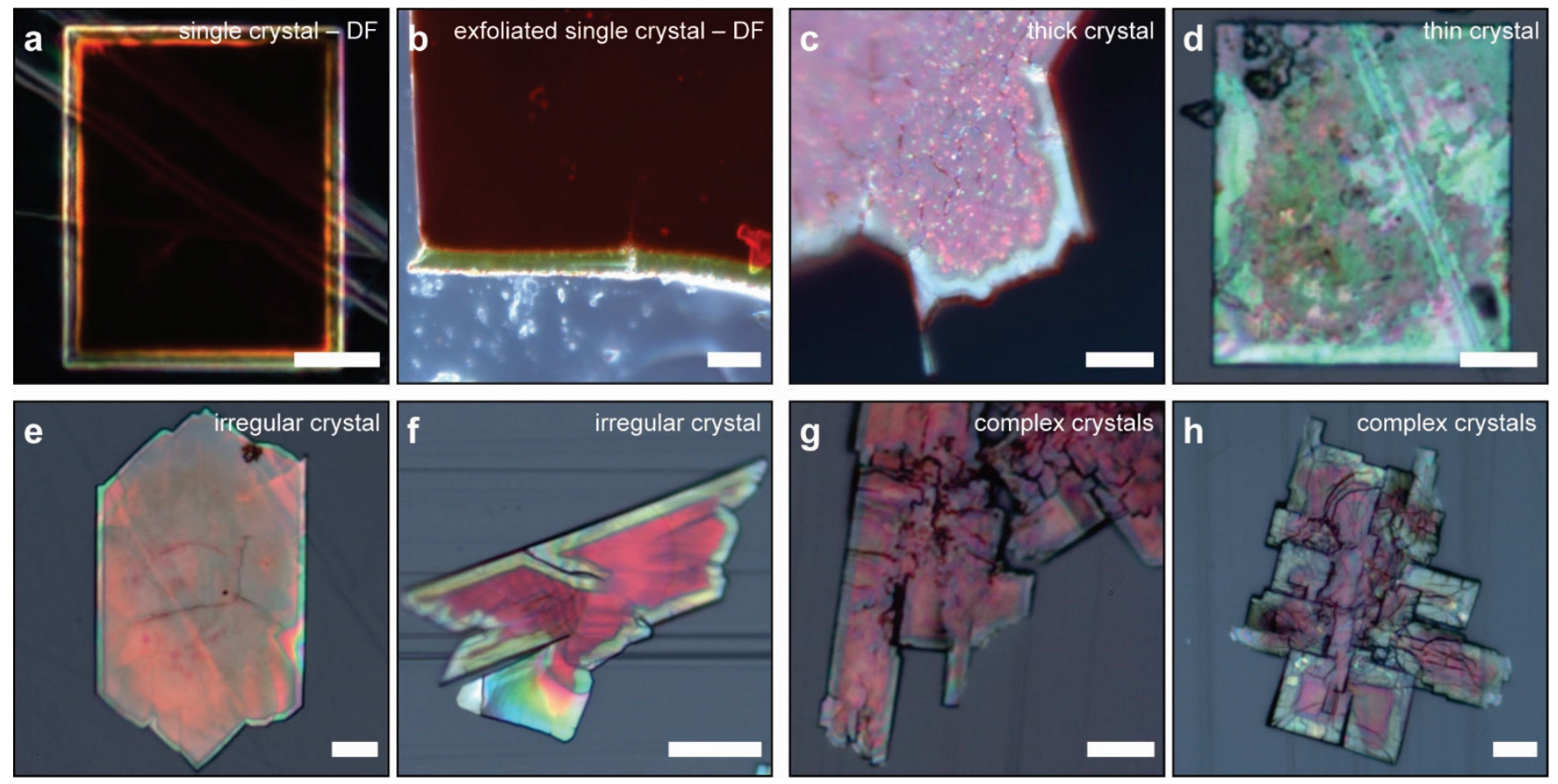

Figure S8. Additional optical micrographs of exchanged $(\mathrm{HA})_{2}(\mathrm{FA}) \mathrm{Pb}_{2} \mathrm{I}_{7} \mathrm{RPP}$ structures with various morphologies. (a) Monocrystalline microplate (dark field image), (b) layer exfoliated from a large single crystal (dark field image), (c) an unexfoliated thick crystal, (d) a thin microplate that has been completely exchanged, (e, f) irregularly shaped microplates, $(\mathrm{g}, \mathrm{h})$ polycrystalline aggregates of microplates. Scale bars are $10 \mu \mathrm{m}$. 


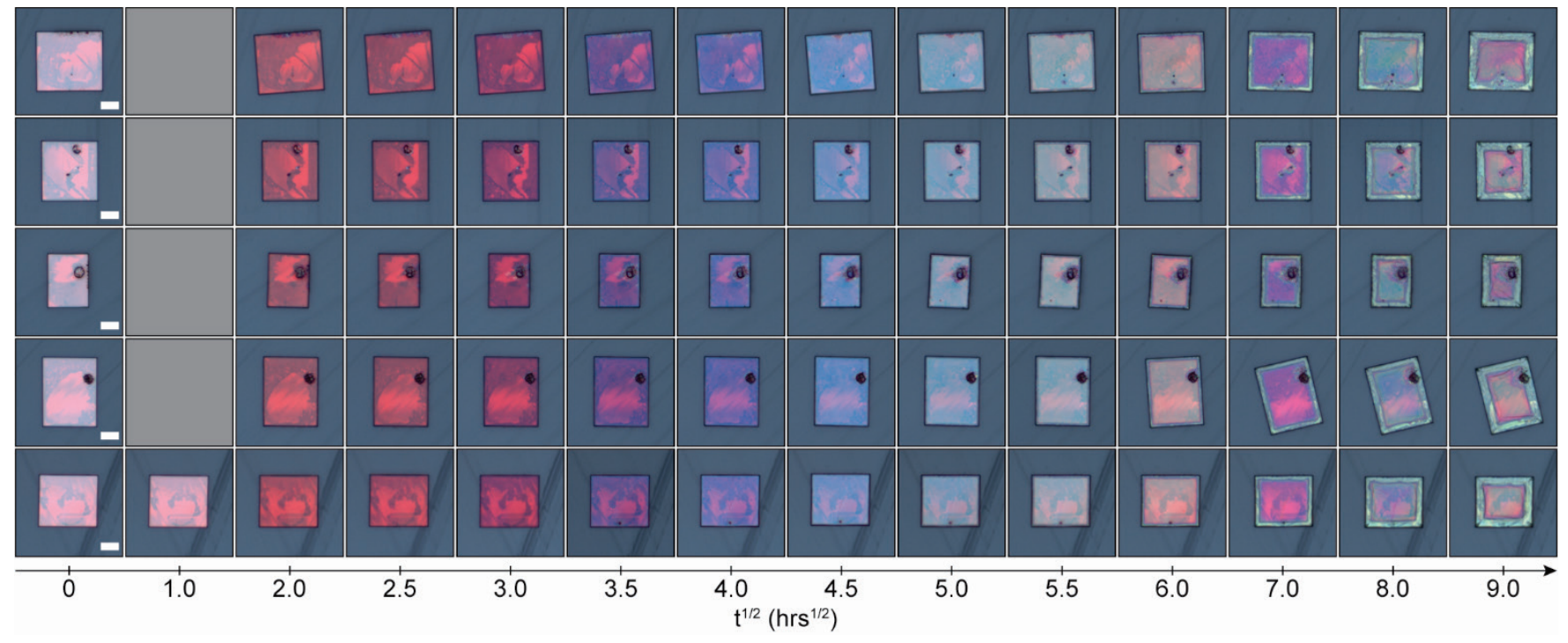

Figure S9. Image matrix for the anion exchange of five $(\mathrm{HA})_{2}(\mathrm{FA}) \mathrm{Pb}_{2} \mathrm{I}_{7}$ microplates as a function of exchange time. Each row follows an individual $(\mathrm{HA})_{2}(\mathrm{FA}) \mathrm{Pb}_{2} \mathrm{I}_{7}$ microplate from a single sample as it undergoes exchange reaction with $\mathrm{HBr}$ vapor. All scale bars are $10 \mu \mathrm{m}$.

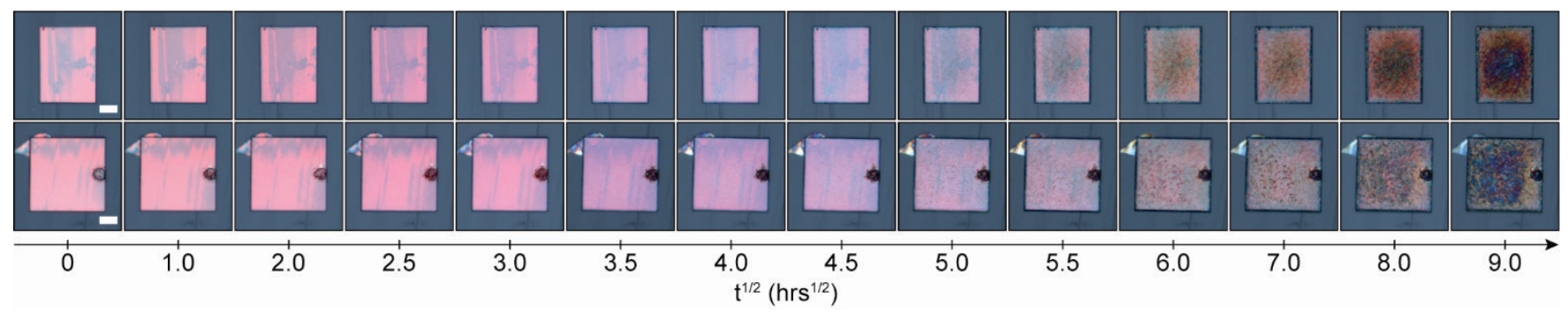

Figure S10. Image matrix for the environmental exposure of two $(\mathrm{HA})_{2}(\mathrm{FA}) \mathrm{Pb}_{2} \mathrm{I}_{7}$ microplates as a function of exposure time. Each row follows an individual (HA) $2(\mathrm{FA}) \mathrm{Pb}_{2} \mathrm{I}_{7}$ microplate over time in ambient conditions. All scale bars are $10 \mu \mathrm{m}$. 

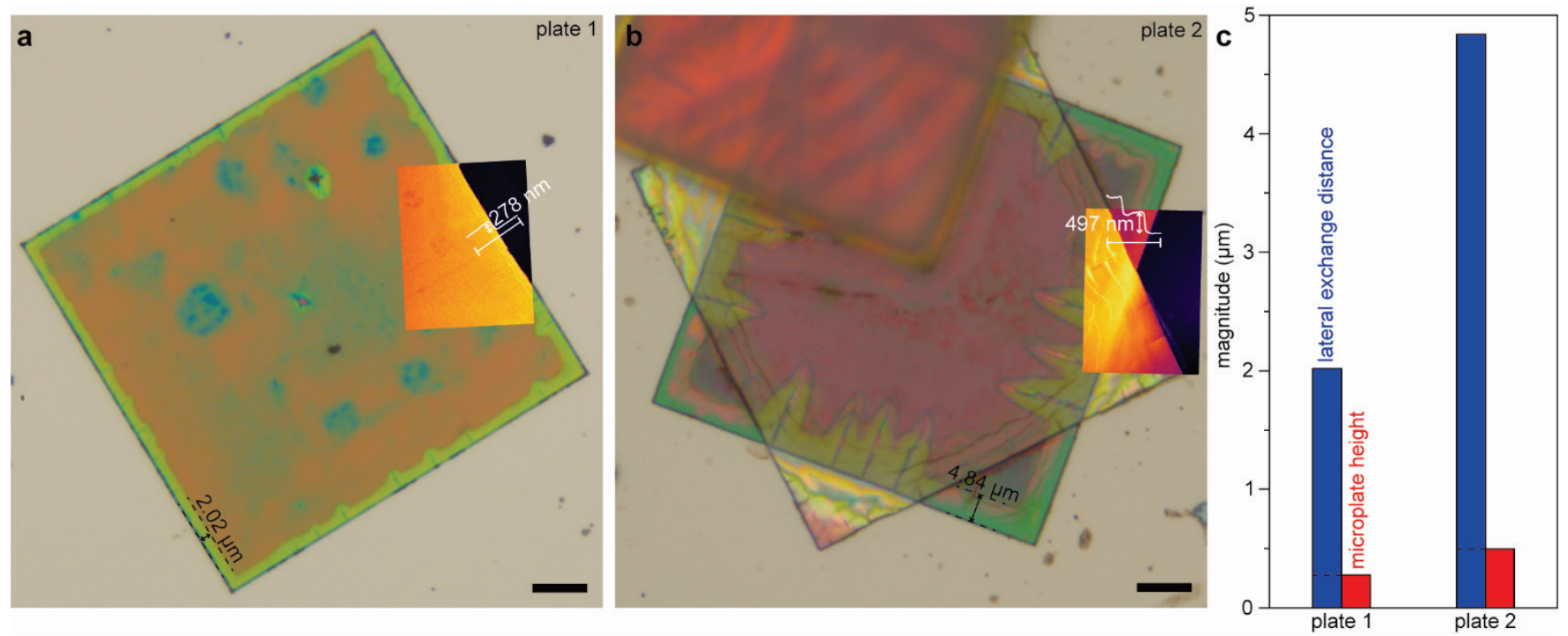

Figure S11. Direct comparison of the height and lateral exchange distance in $n=2 \mathrm{HA}-\mathrm{FA}-\mathrm{Pb}-\mathrm{I} / \mathrm{Br}$ heterostructures. (a-b) Optical micrographs of two $n=2 \mathrm{HA}-\mathrm{FA}-\mathrm{Pb}-\mathrm{I}-\mathrm{Br}$ heterostructures prepared via solution transport and vapor-solid anion exchange with $\mathrm{HBr}$ vapor with overlaid AFM topography images and height profiles (inset false-color images). Scale bars are $10 \mu \mathrm{m}$. (c) Comparison of the lateral exchange distance to the microplate height (measured by AFM) for the microplates imaged in a \& $b$.

\section{Additional discussion of vertical vs. lateral anion exchange rates}

The directly measured heights of the microplates in Figure S7a-b represent the upper bounds of vertical anion exchange for $(\mathrm{HA})_{2}(\mathrm{FA}) \mathrm{Pb}_{2} \mathrm{I}_{7}$. If vertical anion exchange proceeds to completion, the entire $(\mathrm{HA})_{2}(\mathrm{FA}) \mathrm{Pb}_{2} \mathrm{I}_{7}$ microplate would be converted to $(\mathrm{HA})_{2}(\mathrm{FA}) \mathrm{Pb}_{2} \mathrm{Br}_{7}$ and no lateral interface would be visible. Therefore, the observable lateral interfaces in the microplates shown indicate that the vertical exchange depth is less than the height of the microplate. Since the heights of each microplate are nearly an order of magnitude smaller than the widths of the exchanged $(\mathrm{HA})_{2}(\mathrm{FA}) \mathrm{Pb}_{2} \mathrm{Br}_{7}$ at the microplates' edges, it can be concluded that the vertical anion exchange rate is over an order of magnitude slower than the lateral anion exchange rate in $(\mathrm{HA})_{2}(\mathrm{FA}) \mathrm{Pb}_{2} \mathrm{I}_{7}$. 


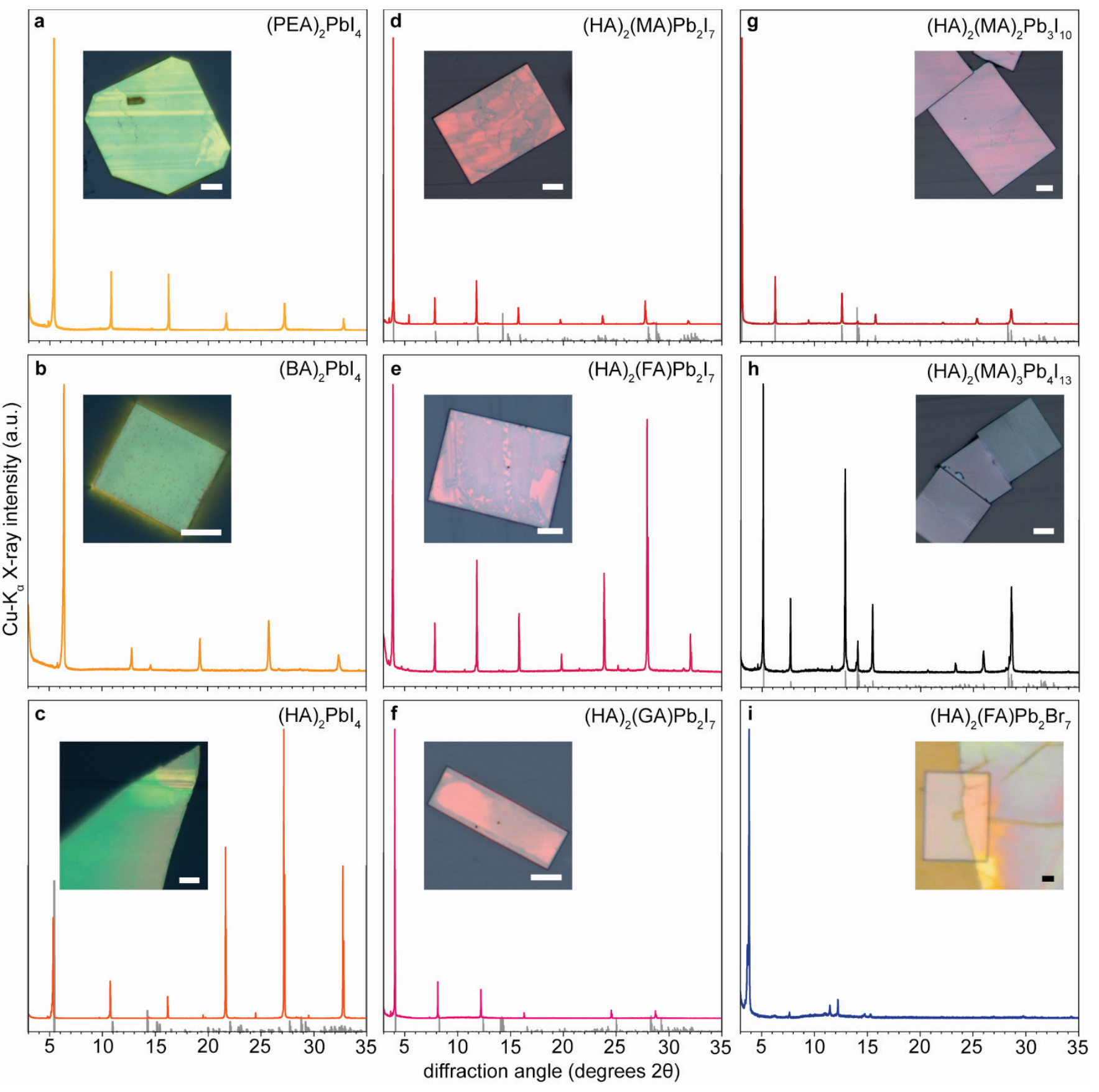

Figure S12. PXRD patterns confirming the crystalline phases of the RPP microplates. Powder X-ray diffraction patterns for all compounds studied in this work. Calculated reflection intensities from available CIFs (CCDC refs.: (a) 200737², (b) 665690, (c) $665695^{3}$, (d) $1904716^{4}$, (f) $1888368^{5}$, (g) 1904714, (h) $1904715^{4}$ ) are presented as gray lines below the experimental patterns. Inset images are optical micrographs of representative microplates. All scale bars are $10 \mu \mathrm{m}$. 


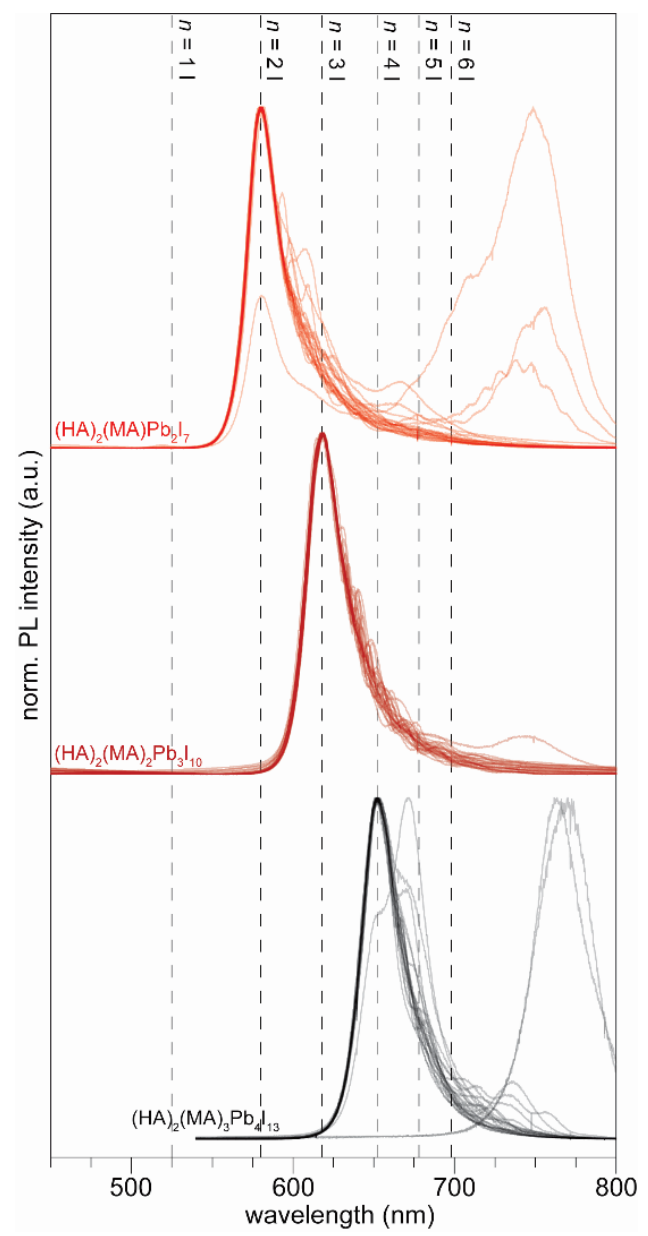

Figure S13. Phase purity and distribution of $n>1$ HA-MA-Pb-I RPP microplates. Confocal PL spectra collected from 25 individual microplates each among samples of $n=2-4$ HA-MA-Pb-I. Reference lines mark emission wavelengths for common lead iodide RPPs of different $n$. 

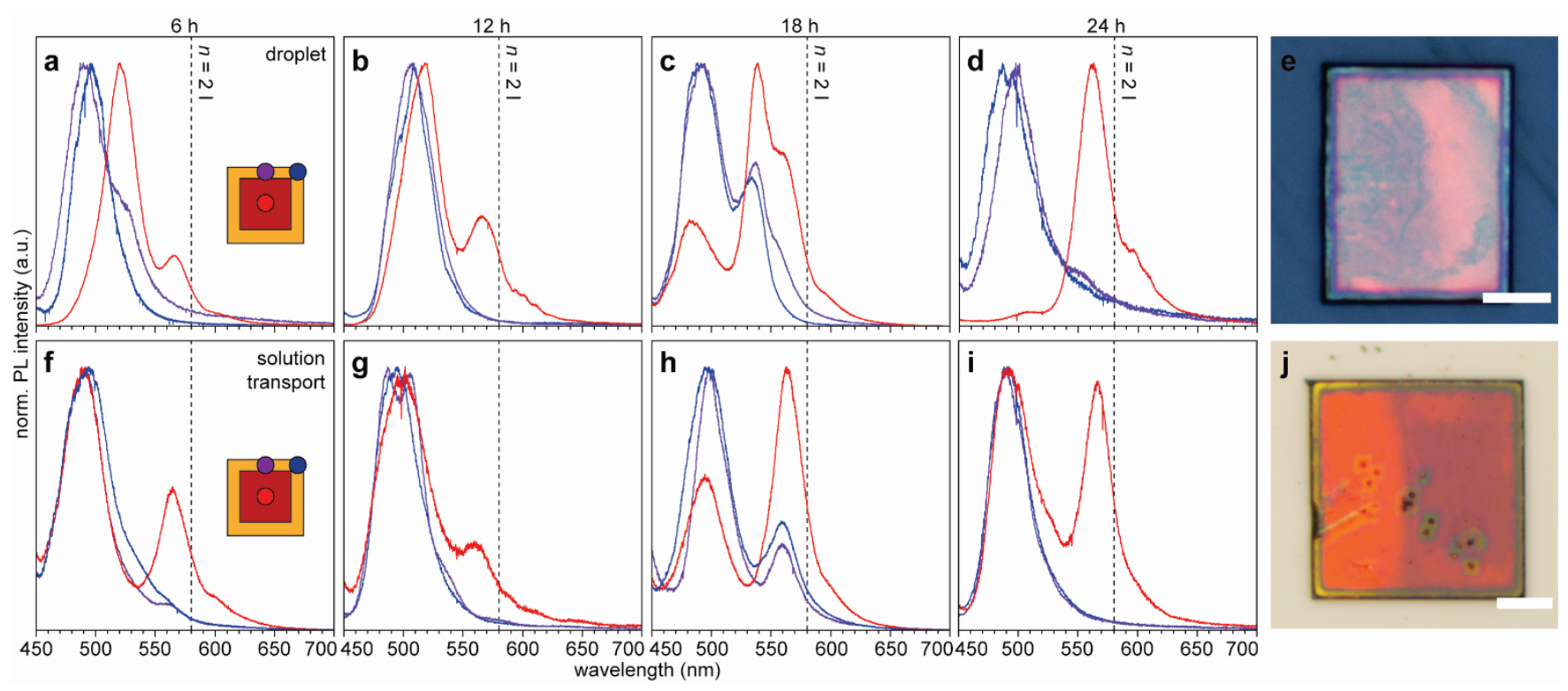

Figure S14. Comparison of exchange behaviors as a function of the synthetic methods used to prepare the starting $(\mathrm{HA})_{2}(\mathrm{FA}) \mathrm{Pb}_{2} \mathrm{I}_{7}$ microplates. Confocal $\mathrm{PL}$ spectra collected from different sections of $(\mathrm{HA})_{2}(\mathrm{FA}) \mathrm{Pb}_{2} \mathrm{I}_{7}$ microplates after incremental anion exchange reaction times with $\mathrm{HBr}$ vapor using (a-d) microplates prepared via aqueous droplet growth, and (f-i) microplates prepared via solution transport growth. Excitation sections are indicated in the inset cartoons of a \& e with colored spots. Reference lines are at the characteristic emission wavelength of $n=2$ iodide RPPs. (e, j) Optical micrographs of representative $n=2 \mathrm{HA}-\mathrm{FA}-\mathrm{Pb}-\mathrm{I} / \mathrm{Br}$ heterostructures prepared via anion exchange with $\mathrm{HBr}$ vapor from starting microplates synthesized via (e) aqueous droplet growth and (j) solution transport growth. Scale bars are $10 \mu \mathrm{m}$. Some samples of $(\mathrm{HA})_{2}(\mathrm{FA}) \mathrm{Pb}_{2} \mathrm{I}_{7}$ had to be synthesized using solution transport to yield intact microplates on a conductive surface because the aqueous droplet method is limited to hydrophobic polymer substrates. This comparison shows that the anion exchange behaviors are qualitatively consistent regardless of how the starting microplates were synthesized. 


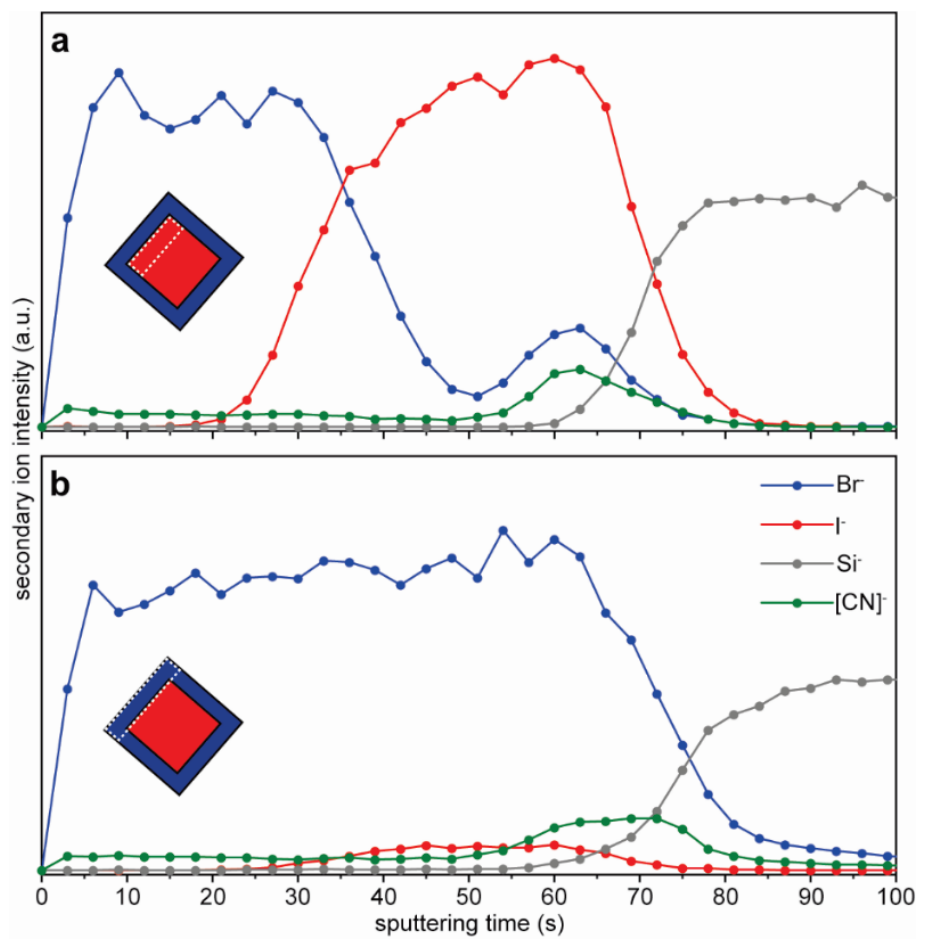

Figure S15. Full SIMS sputtering profiles including the organic ion signals collected on the $n=2$ HA$\mathrm{FA}-\mathrm{Pb}-\mathrm{I} / \mathrm{Br}$ lateral heterostructure. Extended data for the SIMS sputtering profiles collected at the (a) inner and (b) outer components of the heterostructure imaged in main text Fig. 4e, f. Inset cartoons indicate the sputtering areas as white dashed boxes.

\section{Additional interpretation of SIMS sputtering profiles}

There is a notable secondary bromide signal deeper into the plate and just above the silicon substrate in the center sputtering profile, which implies that $\mathrm{HBr}$ can permeate beneath the specimens as prepared here, but to a lesser extent than the exposed top surface. The second bromide peak's correlation with organic ion signals implies that this portion of the sputtering profile is from the interface between the microplate and the substrate, not the microplate itself. This is likely because the surface of the silicon substrate becomes contaminated by traces of the organic reagents in the solution during the dissolutionreprecipitation growth, leaving a layer of organic residue between the plate and the substrate. 


\section{References cited in the supporting information.}

(1) Salvador, M.; Motter, C. E.; McCulloch, I. Hidden Perils of Lead in the Lab: Guidelines for Containing, Monitoring, and Decontaminating Lead in the Context of Perovskite Research. Chem. Mater. 2020, 32 (17), 7141-7149.

(2) Billing, D. G. Bis(1-phenylethylammonium) tetraiodoplumbate(II). Acta Crystallogr. Sect. E 2002, $58(11), \mathrm{m} 669-\mathrm{m} 671$.

(3) Billing, D. G.; Lemmerer, A. Synthesis, Characterization and Phase Transitions in the InorganicOrganic Layered Perovskite-Type Hybrids $\left[\left(\mathrm{C}_{n} \mathrm{H}_{2 n+1} \mathrm{NH}_{3}\right)_{2} \mathrm{PbI}_{4}\right], n=4,5$ and 6. Acta Crystallogr. Sect. B 2007, 63 (5), 735-747.

(4) Spanopoulos, I.; Hadar, I.; Ke, W.; Tu, Q.; Chen, M.; Tsai, H.; He, Y.; Shekhawat, G.; Dravid, V. P.; Wasielewski, M. R.; Mohite, A. D.; Stoumpos, C. C.; Kanatzidis, M. G. Uniaxial Expansion of the 2D Ruddlesden-Popper Perovskite Family for Improved Environmental Stability. J. Am. Chem. Soc. 2019, 141 (13), 5518-5534.

(5) Fu, Y.; Hautzinger, M. P.; Luo, Z.; Wang, F.; Pan, D.; Aristov, M. M.; Guzei, I. A.; Pan, A.; Zhu, X.; Jin, S. Incorporating Large A Cations into Lead Iodide Perovskite Cages: Relaxed Goldschmidt Tolerance Factor and Impact on Exciton-Phonon Interaction. ACS Cent. Sci. 2019, 5 (8), 1377-1386. 